This item was submitted to Loughborough's Research Repository by the author.

Items in Figshare are protected by copyright, with all rights reserved, unless otherwise indicated.

\title{
Cadmium chloride assisted re-crystallisation of CdTe: The effect on the CdS window layer
}

PLEASE CITE THE PUBLISHED VERSION

http://dx.doi.org/10.1557/opt.2015.177

\section{PUBLISHER}

(C) Materials Research Society. Published by the Cambridge University Press (CUP)

\section{VERSION}

AM (Accepted Manuscript)

\section{PUBLISHER STATEMENT}

This work is made available according to the conditions of the Creative Commons Attribution-NonCommercialNoDerivatives 4.0 International (CC BY-NC-ND 4.0) licence. Full details of this licence are available at: https://creativecommons.org/licenses/by-nc-nd/4.0/

\section{LICENCE}

CC BY-NC-ND 4.0

\section{REPOSITORY RECORD}

Abbas, Ali, Piotr M. Kaminski, G.D. West, Kurt L. Barth, Walajabad S. Sampath, Jake W. Bowers, and Michael Walls. 2019. "Cadmium Chloride Assisted Re-crystallisation of Cdte: The Effect on the Cds Window Layer". figshare. https://hdl.handle.net/2134/20609. 


\title{
Cadmium Chloride Assisted Re-Crystallisation of CdTe: The Effect on the CdS Window Layer
}

\author{
Ali Abbas ${ }^{1}$, Piotr Kaminski ${ }^{1}$, Geoff West ${ }^{2}$, Kurt Barth ${ }^{3}$, WS Sampath ${ }^{3}$, Jake Bowers ${ }^{1}$ and \\ John M. Walls ${ }^{1}$ \\ ${ }^{1}$ CREST (Centre for Renewable Energy Systems and Technology), ${ }^{2}$ Department of Materials, \\ Loughborough University, Loughborough, LE11 3TU, United Kingdom \\ ${ }^{3}$ NSF I/UCRC for Next Generation Photovoltaics, Colorado State University, Fort Collins,
} CO 80523, United States

\begin{abstract}
The cadmium chloride annealing treatment is an essential step in the manufacture of efficient thin film CdTe solar cells. In previous work we have shown that the primary effect of the treatment is to remove high densities of stacking faults from the as-deposited material. Use of density functional theory has shown that some of the higher energy stacking faults are hole traps. Removal of these defects dramatically improves cell efficiency. In this study we focus on the effect of the activation treatment on the underlying n-type cadmium sulphide layer. A range of techniques has been used to observe the changes to the microstructure as well as the chemical and crystallographic changes as a function of treatment parameters. Electrical tests that link the device performance with the micro-structural properties of the cells have also been undertaken. Techniques used include High Resolution Transmission Electron Microscopy (HRTEM) for subgrain analysis, EDX for chemical analysis and XPS and SIMS for composition-depth profiling. By studying the effect of increasing the treatment time and temperature, we will show that the cadmium sulphide layer depletes to the point of complete dissolution into the absorber layer. We will also show that chlorine penetrates and decorates the grain boundaries in the cadmium sulphide. In addition we will show that chlorine builds up at the heterojunction and concentrates in voids at the cadmium telluride/cadmium sulphide interface. A combination of these effects damages the electrical performance of the solar cell.
\end{abstract}

\section{INTRODUCTION}

Thin film cadmium telluride (CdTe) solar modules have become an important solar energy source with important applications especially in utility scale installations. Improvements in cell efficiency continue to be made and the record small cell conversion efficiency is now $21 \%$ [1]. CdTe has a direct band gap of $1.45 \mathrm{eV}$ and only a thin layer of the material is needed for total absorption of the solar spectrum $(<2 \mu \mathrm{m})$. These characteristics make it an ideal material for photovoltaic conversion. Thin films of CdTe can be deposited using a number of deposition techniques. In this paper we use close spaced sublimation for both the p-type CdTe layer and the n-type CdS layer. As deposited CdTe/CdS devices provide low conversion efficiency and it is necessary to use a $\mathrm{CdCl}_{2}$ annealing treatment to activate the cells [2]. Previous studies by the present authors have shown that the as deposited material contains high densities of stacking faults and these are completely removed by the activation process [2-4]. Analysis using Density Functional Theory (DFT) has confirmed that some types of stacking faults act as recombination 
centres and are responsible for low device efficiency [5]. Twin boundaries are often observed in activated cells but DFT has shown that these are electrically benign [5]. The activation process is promoted by chlorine diffusion along grain boundaries to the CdS interface where it has been observed to move laterally along the junction and into the CdS layer. An excess of chlorine at the interface causes deterioration in the cell performance [3]. Sulphur has also been observed to diffuse into the CdTe layer causing a thinning of the CdS window layer.

In this paper we report on microstructural studies of the effect of the $\mathrm{CdCl}_{2}$ activation treatment at the CdS/CdTe interface as well as within the CdS layer itself. We map the way in which the chlorine travels down the CdTe absorber along grain boundaries and then into the CdS layer. We provide evidence for lateral movement of chlorine along the junction where it collects in voids. We also track its movement along the interface with the underlying transparent conducting oxide. Elemental mapping also reveals evidence for diffusion of tellurium and sodium.

\section{EXPERIMENTAL PROCEDURES}

\section{Characterization Techniques}

TEM samples were prepared by Focused Ion Beam (FIB) milling using a dual beam FEI Nova 600 Nanolab. A standard in situ lift out method was used to prepare cross-sectional samples through the coating into the glass substrate. A platinum over-layer was deposited to define the surface and homogenize the final thinning of the samples down to $100 \mathrm{~nm}$. Transmission Electron Microscopy (TEM) was undertaken using a Tecnai F20 operating at 200 $\mathrm{kV}$ to investigate the detailed microstructures of the cell cross sections. The system was equipped with an Oxford instruments X-max N80 TLE SDD EDX detector and this was used in STEM mode to collected elemental distribution maps. These maps were collected in a single frame using a long dwell time, as well as a small condenser aperture to minimize drift and beam spread during collection. A Cameca IMS 3F was used for SIMS depth profiling. The analysis was performed using $\mathrm{Cs}^{+}$primary ion bombardment at $10 \mathrm{keV}$ with a current of $1 \mu \mathrm{A}$ with a spot size of $60 \mu \mathrm{m}$ and negative secondary ion detection to optimise the sensitivity to chlorine.

\section{Deposition Conditions}

In this study close spaced sublimated CdTe/CdS cells were deposited using an advanced deposition system developed at Colorado State University (CSU). A pre-cleaned $10 \mathrm{~cm} \mathrm{x} 10 \mathrm{~cm}$ $3 \mathrm{~mm}$ thick soda-lime glass, coated with Pilkingtion's TEC10 fluorine doped tin oxide TCO was placed inverted onto a conveyer system which passed through 8 stations. The inverted substrate enters each deposition station a few millimeters above graphite boats with the sublimation material. The graphite boats were heated, and a secondary heater above the substrate was also used to control deposition rates. The first station annealed the FTO coated glass substrate at a temperature of $620^{\circ} \mathrm{C}$ for 550 seconds. The sample was then transferred to the CdS deposition station where a sublimation temperature of $617^{\circ} \mathrm{C}$ was used with the substrate held at $420^{\circ} \mathrm{C}$, the deposition time was varied according to the thickness required. CdTe was then deposited at a sublimation temperature of $560^{\circ} \mathrm{C}$ with the substrate held at $360^{\circ} \mathrm{C}$. Some samples were then removed at this point and did not undergo further treatments. Two samples underwent a $\mathrm{CdCl}_{2}$ deposition for 180 seconds followed by a 180 second anneal at $400^{\circ} \mathrm{C}$, followed by a copper 
chloride deposition and anneal at $200^{\circ} \mathrm{C}$ for 220 seconds. The samples were allowed to cool before being removed and rinsed with DI water to remove any residual $\mathrm{CdCl}_{2}$.

\section{Samples analyzed}

To investigate the properties of the CdS film, 4 samples were deposited with deliberately thick CdS layers. In a typical device the CdS layer is approximately $100 \mathrm{~nm}$ thick. For the purpose of investigating microstructural, chemical and crystallographic effects the $\mathrm{CdCl}_{2}$ treatment has on the CdS films, cells with $500 \mathrm{~nm}$ and $1000 \mathrm{~nm}$ thick layers of CdS, before and after the treatment were processed and analyzed.

\section{RESULTS}

\section{Microstructural and Chemical Properties of the untreated cell}

Figure 1 shows a bright-field STEM image of the untreated device, the corresponding key elemental distribution maps collected at the CdTe/CdS interface, as well as a high resolution TEM image of this interface.

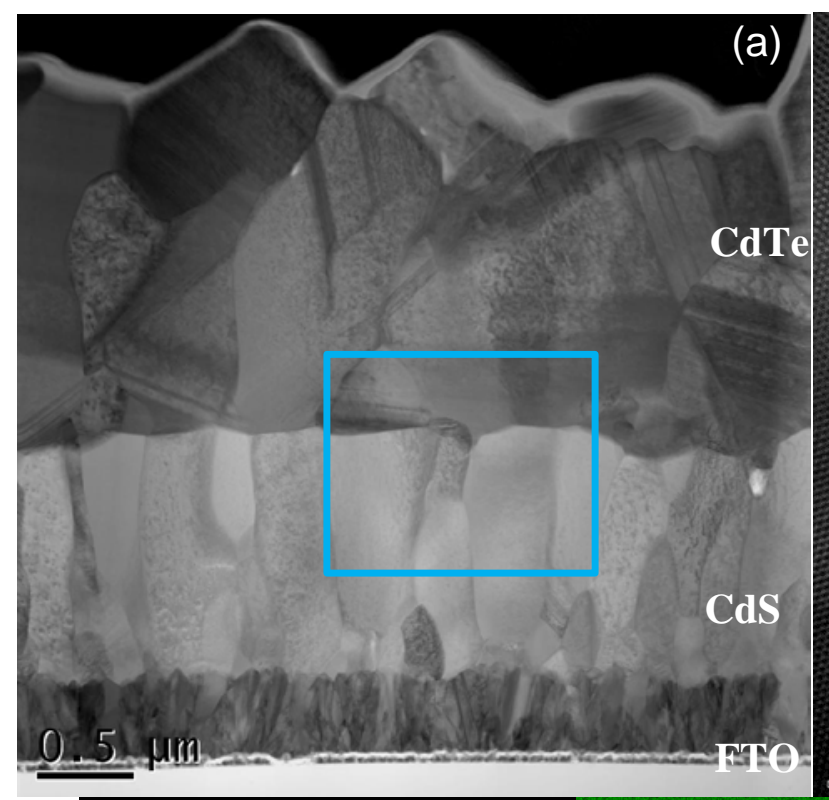

S

(b) Cd

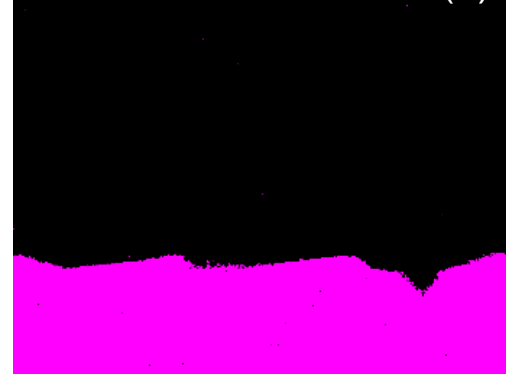
(1)

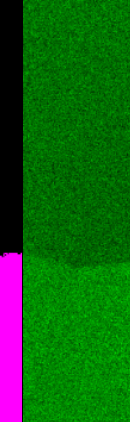

Figure 1 - BF-STEM micrograph of untreated cell (a) with corresponding EDX elemental distribution maps (b-d) and a High Resolution TEM image of the CdS/CdTe interface (e) 
The BF-STEM image in Figure 1a clearly shows large densities of stacking faults within the CdTe grains, as has been reported previously [2]. The CdS layer, which is approximately $1 \mu \mathrm{m}$ thick, consists of columnar grains with no clear sub-grain structure or defects. More detailed analysis of the CdS layer with HR-TEM shown in Figure 1e shows a regular atomic structure without defects. In the interface region with the CdTe layer some distortion of the atom positions can be observed, which can be attributed to the lattice mismatch between the two materials. The elemental distribution maps in Figure 1b-d show no evidence that diffusion had occurred during deposition. This is further supported by the spectra data contained within these maps which showed that in the CdTe side of the interface no sulphur was detected whereas in the CdS side no tellurium was detected.

\section{Microstructural and Chemical Properties of the treated cell}

Figure 2 shows STEM analysis with corresponding EDX derived elemental distribution maps of the CdTe/CdS layers in cross-section, where the CdS layer has a thickness of $120 \mathrm{~nm}$, which is typical in these devices. This analysis shows clear chlorine grain boundary segregation within the CdTe layer and isolated chlorine-rich precipitates at the CdTe/CdS interface. In addition there is apparent chlorine segregation at the $\mathrm{CdTe} / \mathrm{CdS}$ interface and at CdTe grain boundaries. In order to study this interesting observation in more detail a device with a thick $(\sim 1 \mu \mathrm{m})$ CdS layer was fabricated. Sulphur is observed to diffuse from the CdS layer into the CdTe film. The sulphur diffusion into the CdTe is seen in Figure 2 to be predominately along CdTe grain boundaries but diffusing into the bulk of the CdTe grains adjacent to the CdS layer, and to a lesser extent the grains further away from the CdS layer.

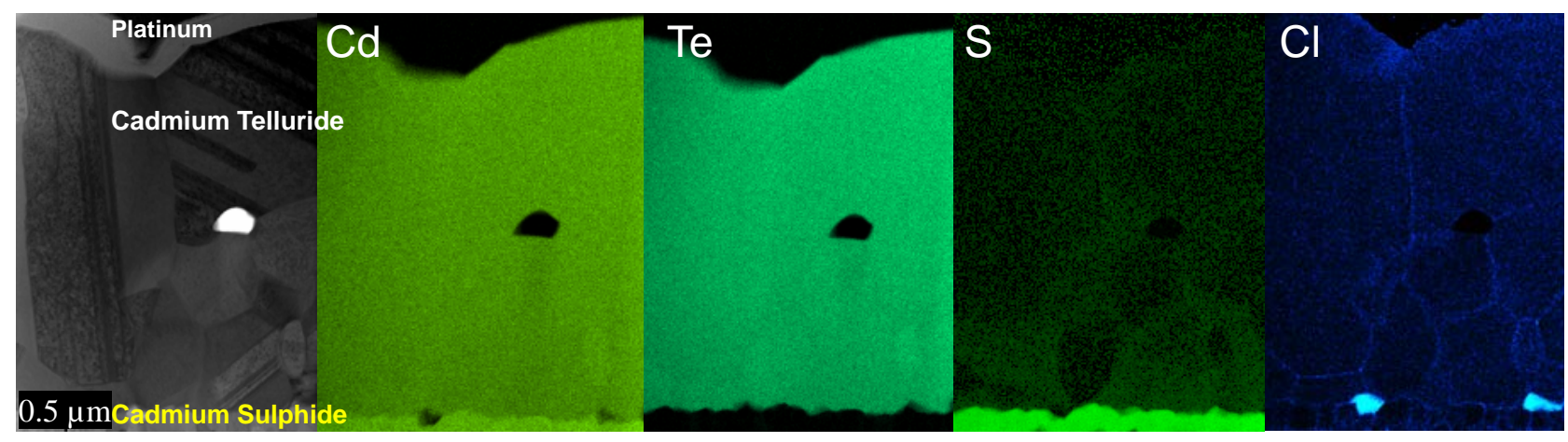

Figure 2 - BF-STEM micrograph of treat cell with CdS layer of typical thickness with corresponding EDX elemental distribution

Figure 3 shows a BF-STEM image of a $\mathrm{CdCl}_{2}$ treated cell with chemical distribution maps of the CdS/FTO interface. This clearly shows grain boundary segregation of chlorine, tellurium and sodium within the CdS layer and at the interface with the FTO. Although the segregation of chlorine along CdTe grain boundaries is well documented [6-7], since the CdS layer is usually only $120 \mathrm{~nm}$ thick the grain boundary chemistry in this layer has not previously been studied in detail. The presence of sodium at the grain boundaries suggests that it has diffused from the substrate glass through the FTO layer. Chlorine is also located along the CdS/FTO interface but does not diffuse into the FTO layer. This suggests that the FTO acts as a barrier to the chlorine halting any further diffusion during the treatment. 


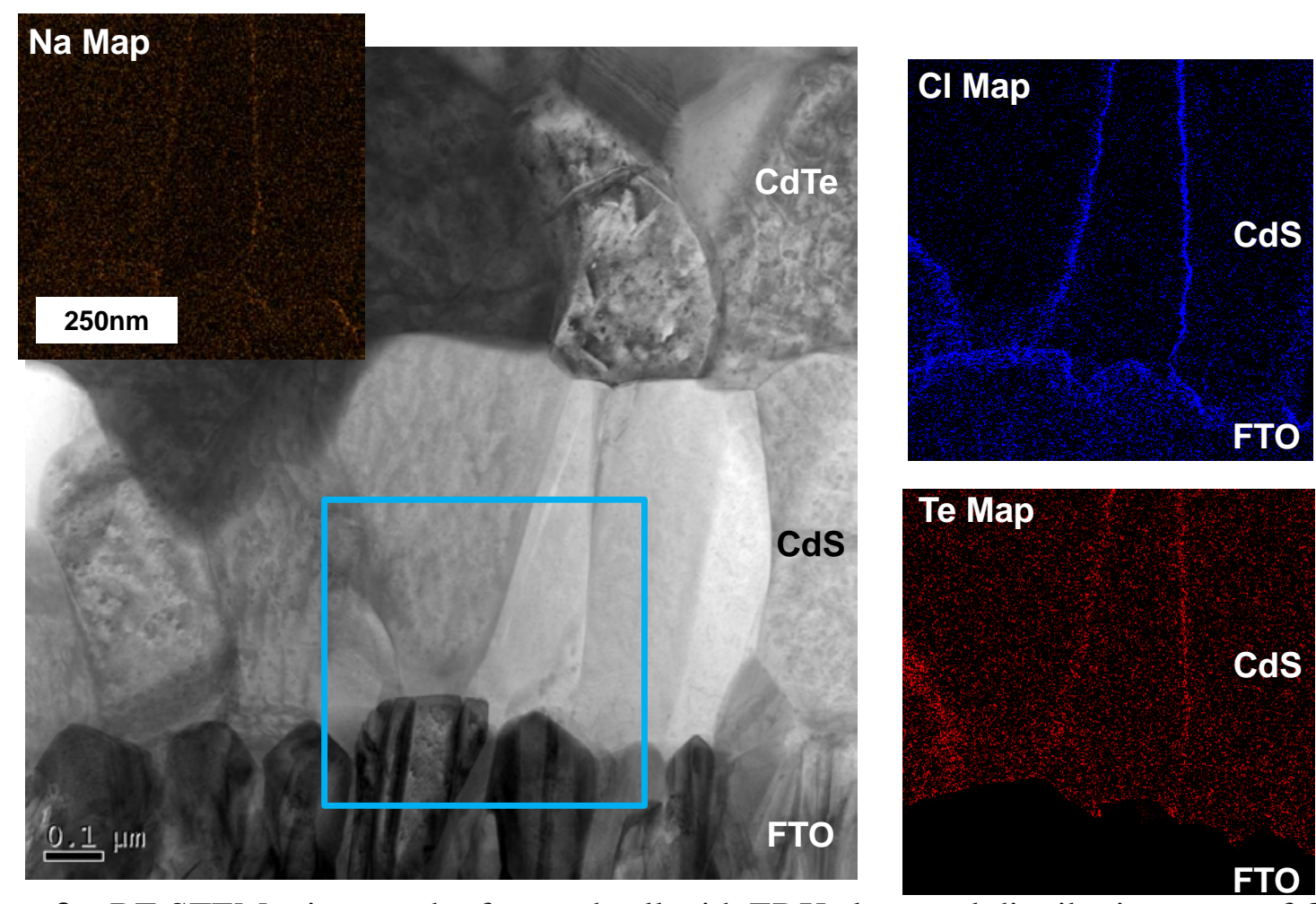

Figure 3 - BF-STEM micrograph of treated cell with EDX elemental distribution maps of Cl, Te and $\mathrm{Na}$ in the CdS/FTO interface region highlighted with the blue box

Figure 4a shows a dynamic secondary ion mass spectrometry (SIMS) depth profile using caesium ions, carried out on the treated sample. The chlorine concentration in the CdTe was quantified. In the bulk CdTe the chlorine concentration is steady at 0.07 at $\%$ increasing slightly to 0.08 at\% until reaching the CdS interface at which it peaks to its maximum concentration 0.7 at\% ten times that within the bulk CdTe. The sulphur concentration with depth can be seen to increase from the surface to the CdS layer, increasing down the CdTe layer toward the CdS. This indicates that as the chlorine is diffusing down the device and the sulphur is diffusing up.
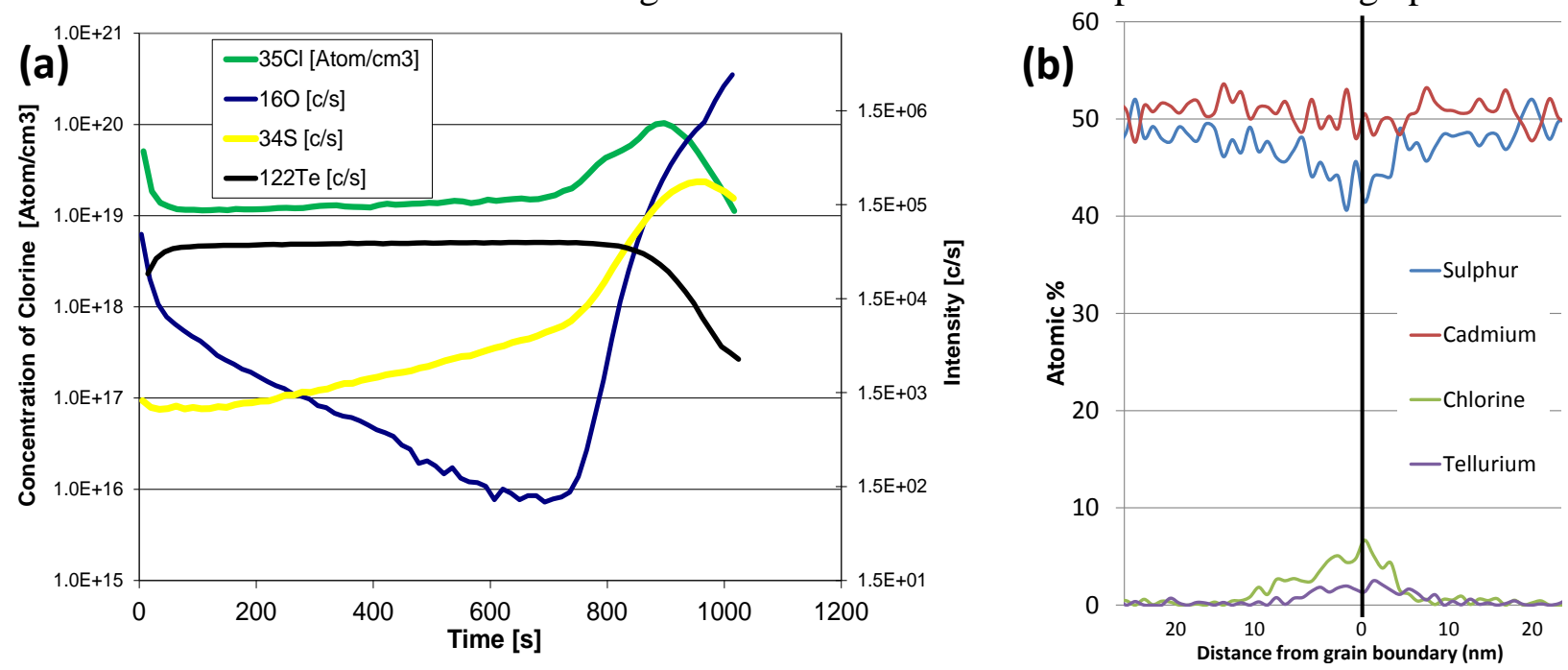

Figure 4 (a) SIMS depth profile of the treated cell (b) EDX line scan across a CdS grain boundary 
Figure $4 \mathrm{~b}$ shows quantitative measurements of elemental segregation along CdS grain boundaries. A maximum of 2 at\% tellurium is observed at the boundary whereas a maximum of 6 at\% of chlorine. The amount of sulphur at the boundary reduces to 41 at $\%$, whereas the cadmium remains steady at 50 at\%. This shows that tellurium and chlorine is displacing the sulphur from the grain boundaries which possibly is the source of the sulphur observed in the CdTe grains.

\section{CONCLUSIONS}

This paper shows during the $\mathrm{CdCl}_{2}$ treatment the $\mathrm{CdS}$ film undergoes alterations, which may be beneficial or detrimental to cell performance. For the first time direct evidence of tellurium diffusion from the CdTe layer into the CdS grain boundaries is observed. Direct observation and quantification of chlorine segregation in the CdTe and CdS grain boundaries is also provided. Low concentrations of sodium, from the glass substrate, have been observed to diffuse through the TCO into the CdS and CdTe layers, which is likely to affect cell performance. Sulphur has been detected by SIMS and EDX to migrate into the CdTe film from the CdS predominately along grain boundaries and into the grains adjacent to the CdS layer. HRTEM images of the CdS show it to be defect free before the $\mathrm{CdCl}_{2}$ treatment.

\section{ACKNOWLEDGMENTS}

The Loughborough authors are grateful to the EPSRC Supergen SuperSolar Hub for financial assistance and the CSU authors to the NSF I/UCRC and AIR programs.

\section{REFERENCES}

1. M. A. Green, K. Emery, Y. Hishikawa, W. Warta and, E. D. Dunlop, (2013), Solar cell efficiency tables (version 42). Prog. Photovolt: Res. Appl., 21: 827-837.

2. Abbas, A; West, G.D.; Bowers, J.W; Isherwood, P.; Kaminski, P.M.; Maniscalco, B.; Rowley, P.; Walls, J.M.; Barricklow, K.; Sampath, W/S.; Barth, K.L, "The Effect of Cadmium Chloride Treatment on Close-Spaced Sublimated Cadmium Telluride Thin-Film Solar Cells," IEEE Journal of Photovoltaics, vol.3, no.4, pp.1361-1366, 2013 doi:10.1109/JPHOTOV.2013.2264995

3. Abbas, A.; West, G.D.; Bowers, J.W.; Kaminski, P.M.; Maniscalco, B.; Walls, J.M.; Sampath, W.S.; Barth, K.L., "Cadmium chloride assisted re-crystallization of CdTe: The effect of the annealing temperature," Photovoltaic Specialists Conference (PVSC), 2013 IEEE 39th , pp.0356-0361, 2013

4. Abbas, A.; Maniscalco, B.; Bowers, J.W.; Kaminski, P.M.; West, G.D.; Walls, J.M., "Initiation of the cadmium chloride assisted re-crystallization process of magnetron sputtered thin film CdTe," Photovoltaic Specialists Conference (PVSC), 2013 IEEE 39th , pp.1930-1934, 2013

5. Yoo, S. H., Butler, K. T., Soon, A., Abbas, A., Walls, J. M., \& Walsh, A. Identification of critical stacking faults in thin-film CdTe solar cells. Applied Physics Letters 105, no. 6, 2014

6. Harvey, S. P., Teeter, G., Moutinho, H. and Al-Jassim, M. M., Direct evidence of enhanced chlorine segregation at grain boundaries in polycrystalline CdTe thin films via threedimensional TOF-SIMS imaging. Prog. Photovolt: Res. Appl. doi: 10.1002/pip.2498, 2014

7. Mao, D.; Wickersham, C.E.; Gloeckler, M., "Measurement of Chlorine Concentrations at CdTe Grain Boundaries," IEEE Journal of Photovoltaics, vol.4, no.6, pp.1655-1658, 2014 